University of Nebraska - Lincoln

DigitalCommons@University of Nebraska - Lincoln

Civil and Environmental Engineering Faculty

Publications

Civil and Environmental Engineering

2016

\title{
Evaluation of the Midwest Guardrail System stiffness transition with curb
}

Jennifer D. Schmidt

University of Nebraska-Lincoln, jennifer.rasmussen@unl.edu

Scott K. Rosenbaugh

University of Nebraska - Lincoln, srosenbaugh2@unl.edu

Ronald K. Faller

University of Nebraska - Lincoln, rfaller1@unl.edu

Follow this and additional works at: https://digitalcommons.unl.edu/civilengfacpub

Schmidt, Jennifer D.; Rosenbaugh, Scott K.; and Faller, Ronald K., "Evaluation of the Midwest Guardrail System stiffness transition with curb" (2016). Civil and Environmental Engineering Faculty Publications. 113.

https://digitalcommons.unl.edu/civilengfacpub/113

This Article is brought to you for free and open access by the Civil and Environmental Engineering at DigitalCommons@University of Nebraska - Lincoln. It has been accepted for inclusion in Civil and Environmental Engineering Faculty Publications by an authorized administrator of DigitalCommons@University of Nebraska Lincoln. 
Published in Journal of Transportation Safety \& Security 9:1 (2017), pp. 105-121, doi: 10.1080/19439962.2015.1134741

Copyright (c) 2017 Taylor and Francis, LLC and The University of Tennessee. Used by permission. Submitted May 27, 2015, accepted November 12, 2015,published online March 4, 2016.

\title{
Evaluation of the Midwest Guardrail System stiffness transition with curb
}

\author{
Jennifer D. Schmidt, Scott K. Rosenbaugh, and Ronald K. Faller \\ Midwest Roadside Safety Facility, University of Nebraska-Lincoln, Lincoln, NE, USA \\ Corresponding author - Jennifer D. Schmidt Midwest Roadside Safety Facility, University of \\ Nebraska-Lincoln, 130 Whittier Building, 2200 Vine Street, Lincoln, NE 68583-0853, USA, email \\ jennifer.schmidt@unl.edu
}

\begin{abstract}
A W-beam to thrie beam stiffness transition with a 102-mm (4- in.) tall concrete curb was developed to connect $787-\mathrm{mm}$ (31-in.) tall W-beam guardrail, commonly known as the Midwest Guardrail System (MGS), to a previously developed thrie beam approach guardrail transition system. This upstream stiffness transition was configured with standard steel posts that are commonly used by several state departments of transportation. The toe of a 102-mm (4-in.) tall sloped concrete curb was placed flush with the backside face of the guardrail and extended the length of the transition region. Three full-scale crash tests were conducted according to the Test Level 3 (TL-3) safety standards provided in AASHTO's Manual for Assessing Safety Hardware (MASH). The first test, MASH Test No. 3-20, was deemed a failure due to guardrail rupture. The stiffness transition was modified to include an additional nested $\mathrm{W}$-beam rail segment upstream from the $\mathrm{W}$ beam to thrie beam transition element. $M A S H$ Test No. 3-20 was repeated on the modified system, and the $1100 \mathrm{C}$ small car was successfully contained and redirected. During MASH Test No. 3-21, a 2270P pickup truck was successfully contained and redirected. Following the crash testing program, the system was deemed acceptable according to the TL-3 safety performance criteria specified in $M A S H$.
\end{abstract}

Keywords: crash test; guardrail stiffness transition; highway safety; $M A S H$; Midwest Guardrail System; roadside Appurtenances 


\section{Introduction}

Approach guardrail transitions are utilized to provide safe vehicle impact redirection when transitioning from semi rigid guardrail systems, like the Midwest Guardrail System (MGS) that has deflected up to 1,114-mm (44-in.) in crash testing (Polivka et al., 2006a,b), to rigid concrete parapets or bridge rails. In 2010, the Midwest Roadside Safety Facility (MwRSF) successfully developed and crash tested a simplified, upstream stiffness transition for connecting 787- $\mathrm{mm}$ (31in.) tall W-beam MGS to thrie beam guardrail transition systems (Lechtenberg et al., 2012; Rosenbaugh et al., 2010), as shown in Figure 1. The upstream stiffness transition consisted of standard 12-gauge Wbeam guardrail, an asymmetrical 10-gauge W-to-thrie segment, and standard 12- gauge thrie beam guardrail. This upstream end stiffness transition was supported using only standard 1.3-m (6-ft) long W6x8.5 steel guardrail posts at various spacings. For testing purposes, a stiff, thrie beam transition system was selected as the downstream end of the full transition (defined as the entire transition from $\mathrm{W}$-beam guardrail to rigid parapet or bridge rail). The downstream end of the transition consisted of nested 12-gauge thrie beam guardrail supported by 2.13-m (7-ft) long W6x15 steel posts spaced at 953-mm (37.5- in.) on center. Crash testing was successfully performed in accordance with the Test Level 3 (TL-3) impact safety standards published in the American Association of State Highway and Transportation Officials (AASHTO) Manual for Assessing Safety Hardware (MASH) (AASHTO, 2009).

Although the system was designed and tested without a curb, several state departments of transportation expressed the desire to use a curb in conjunction with the upstream stiffness transition for drainage control. However, the addition of a curb may negatively affect the performance of the system in a number of ways. For example, small car front ends may become wedged between the curb and the bottom of the W-to-thrie segment that can lead to excessive snagging and rail loads. Additionally, a curb may cause vehicle instabilities and/or rollovers during redirections in this stiffnesssensitive region.

Previous testing has shown that curbs can significantly affect the behavior of approach guardrail transitions. Several full-scale crash tests conducted with pickup trucks according to NCHRP Report 350 (Ross, Sicking, Zimmer, \& Michie, 1993) and MASH TL-3 conditions haven shown that similar transition systems can perform significantly different based on the addition or removal of a curb below the 
guardrail (Alberson, Menges, \& Haug, 2002; Alberson, Menges, \& Schoeneman, 2001; Bligh, Menges, \& Haug, 2003; Faller, Reid, Rohde, Sicking, \& Keller, 1998; Polivka et al., 2006a,b; Williams, Bligh, \& Menges, 2013). Typically, the addition of a curb helped mitigate snag near the downstream end of a transition system. However, the vast majority of transition testing under NCHRP Report 350 (Ross et al., 1993) and $M A S H$ has been conducted with pickups impacting near the downstream end of the transition. The effect of curbs on the upstream end of the transition is largely unknown, especially for small car impacts where the vehicle may get underneath the W-to-thrie transition segment.

\section{Research objective}

The objective of the research project was to evaluate the safety performance of the MGS to thrie beam stiffness transition configured with a concrete curb. The safety performance evaluation was conducted according to MASH TL-3 standards. Thus, the transition with curb system was evaluated through full-scale crash testing with the small car and the pickup vehicles, as detailed below.

1. MASH Test No. 3-20: a 1,100-kg (2,420-lb) passenger car (denoted as an $1100 \mathrm{C}$ vehicle) impacting the system at a nominal speed and angle of $100 \mathrm{~km} / \mathrm{h}(62 \mathrm{mph})$ and 25 degrees, respectively.

2. $M A S H$ Test No. 3-21: a 2,270-kg (5,000-lb) pickup truck (denoted as a $2270 \mathrm{P}$ vehicle) impacting the system at a nominal speed and angle of $100 \mathrm{~km} / \mathrm{h}(62 \mathrm{mph})$ and 25 degrees, respectively.

\section{Preliminary design}

The full-scale crash test installation utilized the same guardrail transition installation (including upstream stiffness transition, downstream transition, and bridge rail) that was previously evaluated according to $M A S H$ (Lechtenberg et al., 2012; Rosenbaugh et al., 2010). Only this time, a 102-mm (4-in.) tall curb was placed below the guardrail. The test installation was $26.7-\mathrm{m}$ (87.5-ft) long, as shown in Figure 2, which consisted of five major structural components: (1) a 3.8-m (12-ft 6-in.) long thrie beam and channel bridge railing system, (2) 3.8-m (12-ft 6-in.) of nested 12-gauge thrie beam guardrail, (3) 1.9$\mathrm{m}$ (6-ft 3-in.) of standard 12-gauge thrie beam guardrail, (4) a 1.9-m (6-ft 3-in.) long, asymmetrical 10-gauge W-to-thrie segment, and (5) $15.2-\mathrm{m}(50-\mathrm{ft})$ of standard 12 -gauge $\mathrm{W}$-beam rail attached to a 
simulated anchorage device. All rails had a top height of 787-mm (31in.), and the lap-splice connections between adjacent rail sections were configured to reduce vehicle snag at the splices.

The guardrail components were supported by two breakaway cable terminal (BCT) timber posts, 16 steel guardrail posts, and three steel bridge posts. Post Nos. 1 and 2 were BCT posts placed in $1.8-\mathrm{m}$ ( $6-\mathrm{ft}$ ) long steel foundation tubes to anchor the system. Post Nos. 3 through 15 were standard 1.8-m (6-ft) long W6x8.5 guardrail posts with 305$\mathrm{mm}$ (12-in.) deep wood blockouts. Post Nos. 16 through 18 were 2.1-m (7-ft) long W6x15 posts with 203-mm (8-in.) deep wood blockouts. The steel posts were placed at various spacings, as shown in Figure 2. The transition was installed within a compacted crushed limestone soil that met AASHTO Grade B gradation specifications and the soil strength requirements of $M A S H$ (AASHTO, 2012).

The transition system's downstream end was connected to a thrie beam and channel bridge railing. Bridge Post Nos. 19 through 21 were W6x20 steel sections measuring 752-mm (29 $/ 8^{-i n}$.) long and were rigidly attached to the top of the concrete tarmac located at the MwRSF's outdoor proving grounds.

A 102-mm (4-in.) tall triangular-shaped curb was selected for use with this system because it is one of the more common curbs used in transition systems. The system was installed with the toe of the curb flush with the back face of the guardrail, as shown in Figure 2. The curb extended from 953-mm (37 $1 / 2^{\text {-in.) }}$ upstream from Post No. 5 until 476-mm (18 $3 / 4^{\text {-in. }) ~ d o w n s t r e a m ~ f r o m ~ P o s t ~ N o . ~ 18 . ~ N o ~ s o i l ~}$ backfill was installed behind the curb, which was considered a worst case scenario for inducing wheel snag on the curb and vehicle instabilities. Further design details of the system are shown in the test report "Dynamic Evaluation of MGS Stiffness Transition with Curb" (Winkelbauer et al., 2014).

\section{Full-scale crash test no. MWTC-1}

The $1100 \mathrm{C}$ vehicle impacted the MGS upstream stiffness transition with curb at a speed of $101.2 \mathrm{~km} / \mathrm{h}(62.9 \mathrm{mph})$ and at an angle of 25.0 degrees. Initial vehicle impact was targeted for $2,381-\mathrm{mm}\left(93 / 4^{-i n}\right.$.) upstream of the W-to-thrie segment, which was selected to maximize the potential for the small car to wedge underneath the guardrail. The same impact point was utilized in previous testing (Lechtenberg et al., 2012; Rosenbaugh et al., 2010). The actual point of impact was 102- 
$\mathrm{mm}$ (4-in.) upstream of the target impact location. A summary of the test results and sequential photographs are shown in Figures 3 and 4 .

The car's front bumper began to under-ride the guardrail upon impact, and the left-front tire overrode the curb. At $0.068 \mathrm{sec}$ after impact, the car began to pitch downward, and at $0.075 \mathrm{sec}$, the front bumper impacted Post No. 9. At $0.118 \mathrm{sec}$, the W-beam guardrail ruptured at the splice between the $\mathrm{W}$-beam and $\mathrm{W}$-to-thrie segment, located at Post No. 9. Subsequently, the vehicle stopped redirecting and began impacting the guardrail posts head-on. The vehicle stopped moving downstream by $0.188 \mathrm{sec}$ after impact but pitched downward over 35 degrees bringing the rear tires above the top of the guardrail. The vehicle eventually came to rest in front of Post No. 11 (4.8 m [15.8 $\mathrm{ft}$ ] downstream of impact) and was facing the barrier. The vehicle trajectory and final position are shown in Figure 3.

Damage to the barrier was severe, as shown in Figure 4. The rail was kinked and flattened throughout the impact region, and Post Nos. 8 through 12 were bent and twisted. The 12-gauge $\mathrm{W}$-beam rail ruptured at the splice at Post No. 9 with all bolts remaining on the downstream end of the ruptured rail, or on the 10 gauge $\mathrm{W}$-to-thrie segment. The guardrail tore from the top, downstream corner of the splice diagonally to the bottom, upstream corner. The downstream edge of the Wbeam remained attached to the W-to-thrie segment. The downstream end of rail folded back and behind the system at Post No. 12. Additionally, a $38-\mathrm{mm}\left(11 / 2^{-i n}\right.$.) vertical tear occurred in the thrie beam at the bottom post bolt of Post No.12. Finally, the top of the curb was gouged in several places from contact with the vehicle bumper and undercarriage.

The damage to the vehicle was moderate with most of the damage occurring on the left side of the vehicle. The left fender, radiator, and headlight were all crushed inward, and the left-front tire was torn. The front bumper and bumper cover were dented and disengaged, the left-front corner of the hood folded under, and the engine cover split. Also, minor spider web cracking occurred in the lower-left corner of the windshield.

The calculated occupant impact velocities (OIVs) and maximum o.010-sec occupant ridedown accelerations (ORAs) in the longitudinal and lateral directions are shown in Figure 2. Note that the OIVs were within the suggested limits provided in $M A S H$, but the longitudinal ORA values exceeded the MASH limits. The measured occupant compartment deformations were all within $M A S H$ limits.

Due to the $\mathrm{W}$-beam rail rupture, the loss of vehicle containment, and the excessive ORA values recorded by the accelerometers, Test No. 
MWTC-1 on the MGS upstream stiffness transition with curb was determined to be unacceptable according to the MASH safety performance criteria for test designation no. 3-20. More comprehensive test results are detailed in the test report "Dynamic Evaluation of MGS Stiffness Transition with Curb" (Winkelbauer et al., 2014).

\section{Modifications and design details}

During Test No. MWTC-1, components of the small car penetrated under the Wbeam rail, while the wheel climbed up and overrode the curb, compressing the suspension. These events led to heavy upward and lateral vehicle loading to the guardrail near the splice between the $\mathrm{W}$-beam and $\mathrm{W}$-to-thrie segment. The vehicle bumper impacting posts as it traveled through this region of the transition further increased the loads applied to the guardrail elements of this splice. Eventually, the $\mathrm{W}$-beam rail ruptured at the splice location, gave way, and allowed the vehicle to snag on a stiff rail element in combination with several exposed transition posts.

The presence of a curb under the MGS upstream stiffness transition likely changed the load direction and magnitude applied to the guardrail in advance of the splice location. In addition, the presence of a curb may also have provided increased soil confinement and/or resistance to post-soil rotation within the guardrail region in advance of the splice location. The wheel interaction with the top and back side edge of the curb may have contributed to an altered vehicle trajectory from that observed in the successful $1100 \mathrm{C}$ test on the system without a curb. Therefore, the left-front fender and tire likely exerted a greater upward force on the system when a curb was present that led to the $\mathrm{W}$-beam rupture at the splice to the $\mathrm{W}$-to-thrie segment.

Because the presence of a curb within the transition caused increased loading to the guardrail segments and lead to rail rupture and excessive occupant risk measures, design modifications were required to strengthen the rail upstream of the $\mathrm{W}$-to-thrie segment. Thus, an additional 12-gauge $\mathrm{W}$-beam segment was incorporated into the system such that $3.8-\mathrm{m}(12.5-\mathrm{ft})$ of nested $\mathrm{W}$-beam guardrail preceded the 10-gauge $\mathrm{W}$-to-thrie segment. This minor modification was believed to be sufficient to prevent rail rupture observed during a small car impact just upstream from the asymmetrical element and in combination with a concrete curb.

Design details for Test Nos. MWTC-2 and MWTC-3 are shown in Figure 5. The system layouts for these two tests are nearly identical to 
that of Test No. MWTC-1 with only the addition of the $3.8-\mathrm{m}(12.5-\mathrm{ft})$ nested $\mathrm{W}$-beam section prior to the $\mathrm{W}$-to-thrie segment.

\section{Full-scale crash test no. MWTC-2}

The 1100C vehicle impacted the MGS upstream stiffness transition with curb at a speed of $98.7 \mathrm{~km} / \mathrm{h}(61.3 \mathrm{mph})$ and at an angle of 25.6 degrees. Initial vehicle impact was targeted for $2,381-\mathrm{mm}\left(93^{3} / 4^{\text {-in. }}\right.$ ) upstream of the $\mathrm{W}$-to-thrie segment, same as the previous test. The actual point of impact was 178-mm (7-in.) downstream of the targeted location. A summary of the test results and sequential photographs are shown in Figures 6 and 7.

Upon impact, the left-front corner of the vehicle under-rode the rail, and the vehicle pitched down. The left-front tire proceeded to override the curb and contact Post Nos. 8 and 9. This time, the rail and splices held together and contained the vehicle as it continued to contact posts within the system. The vehicle was eventually redirected and exited the system $0.312 \mathrm{sec}$ after impact at an angle of 11 degrees. The vehicle came to rest 13.1-m (43.0-ft) downstream of impact and 1.2-m (3.8-ft) laterally in front of the system. The vehicle trajectory and final position are shown in Figure 6.

Damage to the barrier was moderate, as shown in Figure 7. The guardrail was kinked and flattened throughout the impact region, and the rail disengaged from Post Nos. 8 through 10. Post Nos. 8 through 11 were bent back and downstream. The top of the curb had spalling between Post Nos. 7 and 9. The maximum lateral dynamic post and barrier deflections were $366-\mathrm{mm}$ (14.4-in) at Post No. 9 and 417-mm (16.4-in.) at Post No. 8, respectively. The working width of the system was found to be $826-\mathrm{mm}$ (32.5-in).

The majority of the vehicle damage was concentrated on the leftfront corner and left side of the vehicle where the impact occurred. The left-front tire was deflated, disengaged, and came to rest adjacent to Post No. 12. The left-front fender was crushed inward and pushed under the hood. Gouging was found on the fender, the left-front door, and the hood. Finally, the front bumper disengaged from the left side of the vehicle.

The calculated OIVs and ORAs in the longitudinal and lateral directions were within the suggested limits provided in $M A S H$, as shown in Figure 6. Also, deformations to the occupant compartment were minor. Therefore, Test No. MWTC-2, conducted on the MGS upstream stiffness transition with curb, was determined to be acceptable according to the $M A S H$ safety performance criteria for test 
designation no. 3-20. More comprehensive test results are detailed in the test report "Dynamic Evaluation of MGS Stiffness Transition with Curb" (Winkelbauer et al., 2014).

\section{Full-scale crash test no. MWTC-3}

The 2270P pickup impacted the MGS upstream stiffness transition with curb at a speed of $98.2 \mathrm{~km} / \mathrm{h}(61.0 \mathrm{mph})$ and at an angle of 24.4 degrees. The vehicle impacted the target impact point at $1,905-\mathrm{mm}$ (75-in.) upstream of the $\mathrm{W}$-to-thrie segment. This impact point was identical to previous testing of the transition without curb and was selected to maximize the potential for pocketing, snag on guardrail posts, and loading to the transition element (Lechtenberg et al., 2012; Rosenbaugh et al., 2010). A summary of the test results and sequential photographs are shown in Figures 8 and 9.

Upon impact, Post Nos. 7 through 10 began deflecting backward. The left-front tire overrode the curb $0.044 \mathrm{sec}$ after impact and underrode the guardrail 0.070 sec after impact. The tire then contacted Post No. 9 and detached from the vehicle. The posts and the rail continued to deflect backward as the vehicle was captured and redirected. The vehicle became parallel to the system at $0.218 \mathrm{sec}$ and exited the system $0.326 \mathrm{sec}$ after impact at an angle of 12 degrees. The vehicle came to rest $30.8-\mathrm{m}(101-\mathrm{ft})$ directly downstream of impact. The vehicle trajectory and final position are shown in Figure 8.

Damage to the barrier was moderate, as shown in Figure 9. The guardrail was kinked and flattened throughout the impact region and disengaged from Post Nos. 6, 8, and 10 through 12. Post Nos. 7 through 12 were bent back and downstream. The maximum lateral dynamic post and rail deflections were 607-mm (23.9-in.) and 559-mm (22.0in.), respectively, at Post No. 10. The working width of the system was found to be $1,036-\mathrm{mm}$ (40.8-in.).

The damage to the vehicle was concentrated on the left-front corner and left side of the vehicle where impact occurred. The left-front bumper and quarter panel was deflected inward, and the left-front wheel was disengaged from the vehicle. The left-front door was dented, and the left side of the windshield had spider-web cracking.

The calculated OIVs and ORAs in the longitudinal and lateral directions were within the suggested limits provided in $M A S H$ and are shown in Figure 8. Also, deformations to the occupant compartment were minor. Therefore, Test No. MWTC-3, conducted on the MGS upstream stiffness transition with curb, was determined to be acceptable according to the $M A S H$ safety performance criteria for test 
designation no. 3-21. More comprehensive test results are detailed in the test report "Dynamic Evaluation of MGS Stiffness Transition with Curb" (Winkelbauer et al., 2014).

\section{Summary and conclusions}

The objective of this study was to evaluate the MGS upstream stiffness transition between $\mathrm{W}$-beam guardrail and thrie beam transitions to bridge rails with a 102- $\mathrm{mm}$ (4-in.) tall curb. In 2010, the stiffness transition configuration, shown in Figure 10a, was successfully crash tested without a curb (Lechtenberg et al., 2012; Rosenbaugh et al., 2010). However, when a 102-mm (4-in.) tall curb was present with that system, the front end of the $1100 \mathrm{C}$ vehicle penetrated under the $\mathrm{W}$-beam rail at the same time that the wheel climbed up and over-rode the curb. The combination of these events caused upward and lateral loads being imparted to the rail elements that eventually caused the $\mathrm{W}$-beam rail to rupture at the splice adjacent to the $\mathrm{W}$-to-thrie segment. The loss of containment led to the vehicle impacting transition posts head on causing ORA values above the $M A S H$ limits. Therefore, the previously tested MGS upstream stiffness transition was not acceptable for use with curbs.

After the failed crash test, the design was modified to incorporate an additional 12-gauge $\mathrm{W}$-beam segment such that $3.8-\mathrm{m}(12.5-\mathrm{ft})$ of nested guardrail preceded the asymmetric W-to-thrie segment, as shown in Figure 10b. Subsequently, MASH Test Designation 3-20 was repeated, and the $1100 \mathrm{C}$ small car was safely contained and redirected. A second test was then conducted on the modified transition according to MASH Test Designation 3-21, and the 2270P pickup truck was also safely contained and redirected. Upon the successful completion of the MASH TL- 3 Testing Matrix, the modified upstream stiffness transition (between the MGS and thrie beam guardrail transition) with curb was found to satisfy current safety standards.

Because a very stiff thrie beam approach guardrail transition was used in the full-scale crash testing program, the upstream stiffness transition developed herein should be applicable to most other thrie beam approach guardrail transition systems. Details concerning the attachment of the upstream stiffness transition to other thrie beam transition systems can be found in the 2010 report on the original development of the stiffness transition (Rosenbaugh et al., 2010).

The use of nested $\mathrm{W}$-beam rail at the upstream end of the $\mathrm{W}$-tothrie segment will be required for transition installations that utilize curbs. The use of nested rail was shown to sufficiently increase the 
strength of the system and prevent rail tearing. Additionally, rail nesting adjacent to the upstream end of the $\mathrm{W}$-to-thrie segment aided to decrease vehicle pocketing and snag. These same benefits could also be gained if the modified (nested) version of the upstream stiffness transition was utilized for installations without curbs. The system performance during crash tests without curbs (Test Nos. MWTSP-3 and MWTSP-2) and with curbs (Test Nos. MWTC-2 and MWTC-3) were similar, only the system tested with a curb was stiffer with the nested section and curb and had lower dynamic deflections (Rosenbaugh et al., 2010; Winkelbauer et al., 2014). The upstream stiffness transitions were impacted by $1100 \mathrm{C}$ small cars at the same impact location and dynamically deflected 470-mm (18.5-in.) in Test No. MWTSP-3 and 417-mm (16.4-in.) in Test No. MWTC-2. The upstream stiffness transitions were impacted by $2270 \mathrm{P}$ pickup trucks at the same impact location and dynamically deflected 833-mm (32.8-in.) in Test No. MWTSP-3 and 607-mm (23.9-in.) in Test No. MWTC-2. A graphical comparison of the transition systems' performance when impacted by small cars and pickup trucks is shown in Figure 11. Thus, system installations without curbs have the option to use either the original MGS upstream stiffness transition design or the modified (nested) MGS upstream stiffness transition. The final configurations of the stiffness transitions with and without a curb are shown in Figure 10.

Although the $\mathrm{W}$-beam to thrie beam stiffness transition (upstream portion of a full approach transition) evaluated herein can be utilized with or without a curb, many of the thrie beam approach transitions (downstream portions of a full transition system that attach to rigid parapets or bridge rails) are sensitive to the use of curbs. As described earlier, the addition or removal of a curb under the downstream end of a transition has been shown to greatly affect the safety performance of transitions during full-scale crash testing, sometimes to the extent of passing or failing the test criteria. As such, care should be taken to only utilize curbs with guardrail transition systems that have been developed, tested, and approved for use with curbs.

The rail tearing and failure observed in Test No. MWTC-1 may have implications for guardrail installations over curbs beyond this stiffness transition system. To date, 787-mm (31-in.) high W-beam guardrail systems in combination with curbs have only been evaluated in full-scale testing with large pickups. It is possible that small car impacts on other 787-mm (31-in.) high W-beam systems installed over curbs could impart similar combined lateral and vertical loads to the rail elements and result in similar rail tearing. Therefore, further 
evaluation of small car impacts into $787-\mathrm{mm}$ (31-in.) high W-beam systems in combination with curbs may be warranted.

\section{Installation recommendations}

To ensure the safety performance of the transition, the 102-mm (4-in.) tall curb should be placed through the entire length of the stiffness transition. Thus, the curb should be extended from the bridge and through the nested $\mathrm{W}$-beam section before either being terminated or transitioning to another curb type. Curbs taller than 102-mm (4-in.) are not recommended to be utilized with approach guardrail transitions without further evaluation. Additionally, it is recommended to utilize a minimum length of $0.9-\mathrm{m}(3-\mathrm{ft})$ for any curb shape transitions or terminations (e.g., transitioning from 102-mm [4in.] curb to no curb).

The curb was installed above ground line and without additional soil backfill. Thus, the ground surface underneath and behind the barrier remained level with the roadway surface and not the top of curb. This configuration was selected as a critical test design as it allows vehicle wheels to snag or catch on the backside of the curb, thus potentially leading to increased propensity for vehicle instabilities or wheel/bumper snag on strong posts. However, if the soil behind the curb was backfilled to match the height of the curb, the extra 102-mm (4-in.) of soil backfill would result in increased post embedment, increased post-soil resistance, and a slightly stiffer and stronger barrier system. Impacts into the stiffened transition system would likely result in reduced lateral barrier displacements and less vehicle snag. Thus, it is believed that installations utilizing soil backfill would also perform acceptably.

The tested system had 10.5-m (34 ft 41/2 in.) of standard MGS between the upstream end of the stiffness transition (nested rail segments) and the upstream BCT wood anchor post. Guardrail end terminals are designed, crash tested, and evaluated for use when directly attached to semi rigid $\mathrm{W}$-beam guardrail systems, instead of stiffer approach guardrail transitions. The introduction of stiffer (nested) rail segments may potentially lead to degraded performance of crashworthy terminals. Additionally, placement of the upstream end anchorage too close to the stiffness transition may negatively affect system performance and potentially result in excessive barrier deflections, vehicle pocketing, wheel snagging on posts, vehicle tobarrier override, or other vehicle instabilities. Thus, the following implementation guidelines should be considered when utilizing the 
modified MGS stiffness transition. Although the reference point was changed to the upstream end of the nested rail segment, these recommendations result in the same system lengths upstream of the W-to-thrie segment that were recommended previously for the original transition system design without nesting (Rosenbaugh et al., 2010).

1. The length of W-beam guardrail installed upstream of the nested Wbeam section is recommended to be greater than or equal to the total system length of an acceptable TL-3 guardrail end terminal. Thus, the guardrail terminal's interior end (identified by stroke length) should not intrude into the nested W-beam section of the modified MGS stiffness transition.

2. A recommended minimum barrier length of $10.5-\mathrm{m}\left(34 \mathrm{ft} 4^{1 /} / 2^{\mathrm{in}}\right.$.) is to be installed beyond the upstream end of the nested $\mathrm{W}$-beam section, which includes standard MGS, a crashworthy guardrail end terminal, and an acceptable anchorage system.

3. For flared guardrail applications, a minimum length of 3.8-m (12.5$\mathrm{ft}$ ) is recommended between the upstream end of the nested $\mathrm{W}$ beam section and the start of the flared section (i.e., bend between flare and tangent sections).

The MGS stiffness transition with curb was successfully crash tested with all posts installed in level terrain. Therefore, this upstream stiffness transition (and all other guardrail transitions tested on level terrain) should be implemented with a minimum of $0.6-\mathrm{m}(2-\mathrm{ft})$ of level or gently-sloped fill placed behind the posts, unless special design provisions are made to account for decreased post-soil resistance. Additionally, it is unknown as to whether a nonblocked version of the MGS installed adjacent to the new stiffness transition will negatively affect the system. The safety performance of nonblocked MGS in conjunction with the modified stiffness transition can only be verified through the use of full-scale crash testing. As such, it is recommended that a minimum of $3.8-\mathrm{m}(12.5-\mathrm{ft})$ of standard MGS with spacer blocks be placed adjacent to the modified stiffness transition (upstream end of the nested rail section) prior to transitioning to a nonblocked, 787-mm (31-in.) tall, W-beam guardrail system.

Acknowledgments - The authors wish to acknowledge several sources that made a contribution to this project: MwRSF personnel for constructing the barriers and conducting the crash tests and IMH Products, Inc., for assistance with the asymmetric W-to-thrie segment. 
Funding - The authors wish to acknowledge the Midwest States Regional Pooled Fund Program for sponsoring this project.

\section{References}

Alberson, D. C., Menges, W. L., \& Schoeneman, S. K. (2001). NCHRP report 350 test 3-21 on the Ohio type 1 transition from thrie beam to concrete parapet with asphalt curb (Report No. 401021-5). College Station, TX: Texas A\&M University, Texas Transportation Institute.

Alberson, D. C., Menges, W. L., \& Haug, R. R. (2002). NCHRP report 350 test 3-21 of the Ohio transition at the 10-gauge non-symmetrical type 2 transition section (Report no. 401021-6). College Station, TX: Texas Transportation Institute, Texas A\&M University.

American Association of State Highway and Transportation Officials (AASHTO). (2009). Manual for assessing safety hardware. Washington, DC: American Association of State Highway and Transportation Officials.

American Association of State Highway and Transportation Officials (AASHTO). (2012). Standard specification for materials for aggregate and soil-aggregate subbase, base, and surface courses (designation M147-65). Washington, DC: AASHTO.

Bligh, R. P., Menges, W. L, \& Haug, R. P. (2003). Evaluation of guardrail to concrete bridge rail transitions (Report no. FHWA/TX-04/4564-1). College Station, TX: Texas A\&M University, Texas Transportation Institute,.

Faller, R. K., Reid, J. D., Rohde, J. R., Sicking, D. L., \& Keller, E. A. (1998). Two approach guardrail transitions for concrete safety shape barriers (Report No. TRP-03-69-98). Lincoln, NE: University of Nebraska-Lincoln, Midwest Roadside Safety Facility.

Lechtenberg, K. A., Rosenbaugh, S. K., Bielenberg, R. W., Mongiardini, M., Faller, R. K., \& Albuquerque, F. D. B. (2012). Development and implementation of the simplified Midwest guardrail system stiffness transition. Transportation Research Record, 2309, 81-93.

National Safety Council. (1971). Vehicle damage scale for traffic investigators (2nd ed., Technical Bulletin No. 1). Chicago, IL: Traffic Accident Data Project.

Polivka, K. A., Faller, R. K., Sicking, D. L., Rohde, J. R., Bielenberg, R. W., \& Reid, J. D (2006a). Performance evaluation of the Midwest Guardrail System-Update to NCHRP 350 test no. 3- 11 with 28" C.G. height (2214MG-2), final report to the National Cooperative Highway Research Program (Report No. TRP-03-171-06). Lincoln, NE: University of Nebraska-Lincoln, Midwest Roadside Safety Facility.

Polivka, K. A., Faller, R. K., Sicking, D. L., Rohde, J. R., Bielenberg, R. W., Reid, J. D., \& Coon, B. A. (2006b). Performance evaluation of the guardrail to concrete barrier transition-Update to NCHRP 350 test no. 3-21 with 28" C.G. height (2214T-1), Final report to the National Cooperative Highway Research Program (Report No. TRP-03-175-06). Lincoln, NE: University of Nebraska-Lincoln, Midwest Roadside Safety Facility. 
Rosenbaugh, S. K., Faller, R. K., Bielenberg, R. W., Lechtenberg, K. A., Sicking, D. L., \& Reid, J. D. (2010). Development of the MGS approach guardrail transition using standardized steel posts (Report No. TRP-03-210-10). Lincoln, NE: University of Nebraska-Lincoln, Midwest Roadside Safety Facility.

Ross, H. E., Sicking, D. L., Zimmer, R. A., \& Michie, J. D. (1993). Recommended procedures for the safety performance evaluation of highway features (National Cooperative Highway Research Program Report 350). Washington, D.C.:, Transportation Research Board of the National Academies

Society of Automotive Engineers (SAE). (1985). Collision deformation classification-Recommended practice J224 March 1980 (Handbook Vol. 4)., Warrendale, PA: SAE.

Williams, W. F., Bligh, R. P., \& Menges, W. L. (2013). MASH TL-3 testing and evaluation of the TXDOT T131RC bridge rail transition (Report no. FHWA/TX-13/9-1002-12-4). College Station, TX: Texas A\&M University, Texas Transportation Institute.

Winkelbauer, B. J., Putjenter, J. G., Rosenbaugh, S. K., Lechtenberg, K. A., Bielenberg, R. W., Faller, R. K., \& Reid, J. D. (2014). Dynamic evaluation of MGS stiffness transition with curb (Transportation Research Report No. TRP-03-291-14). Lincoln, NE: University of Nebraska-Lincoln, Midwest Roadside Safety Facility.

\section{Figures}

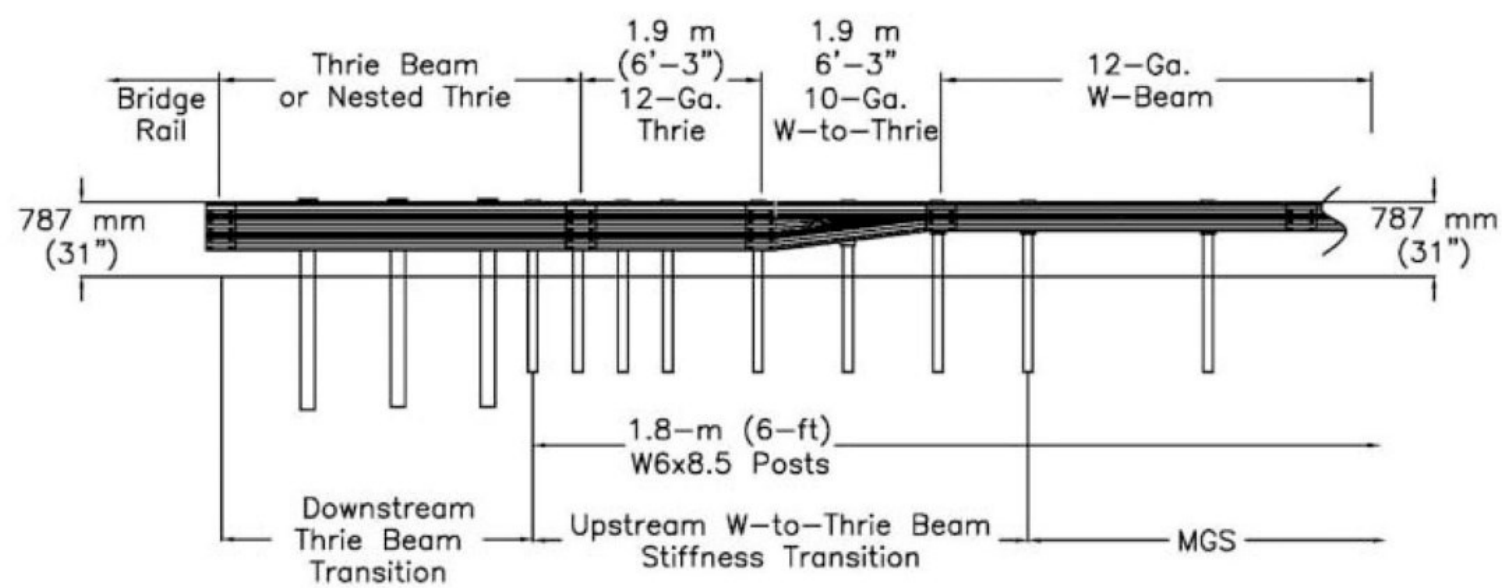

Fig. 1. Approach guardrail transition system (Rosenbaugh et al., 2010). 


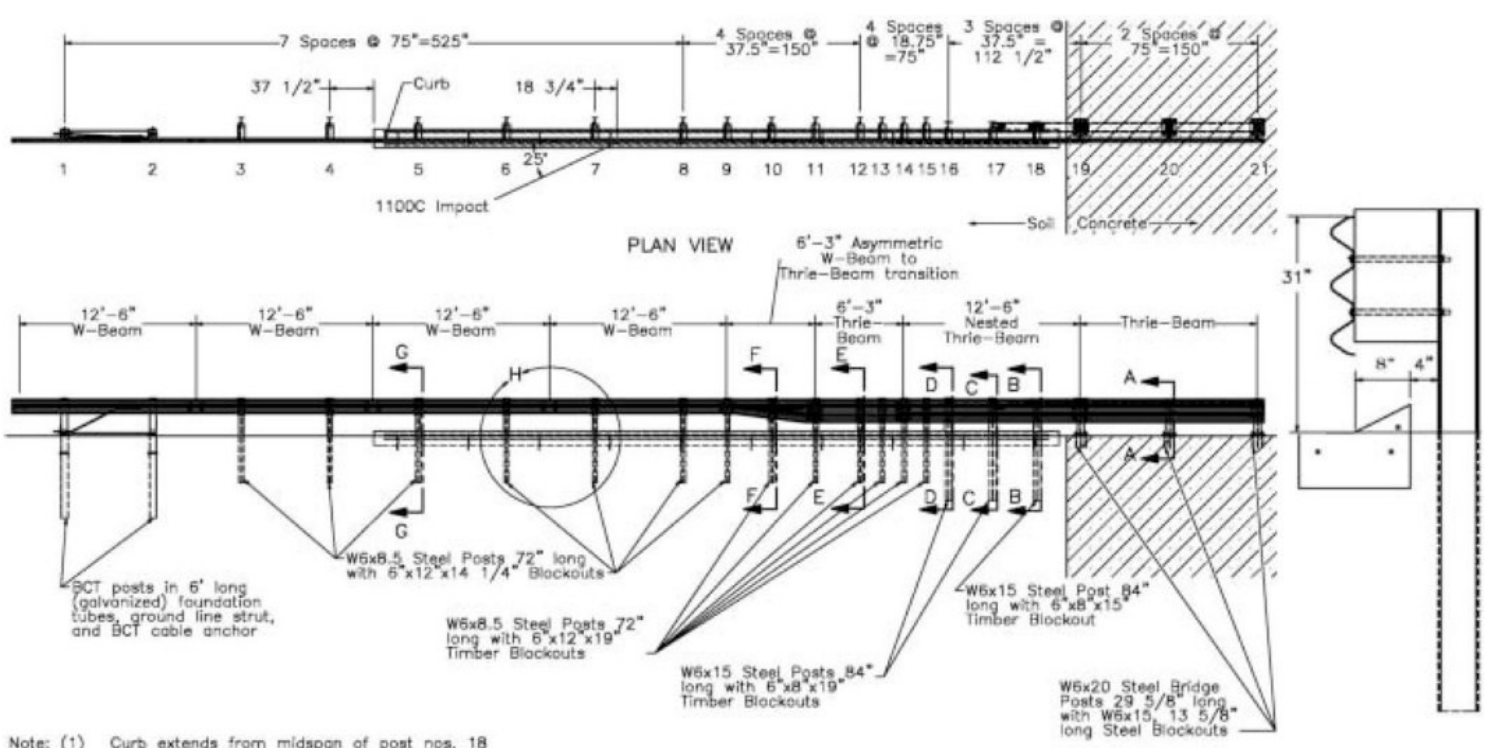

Note: (1) Curb extends fram midspon of post nos. 18
and 19 to midspan of post nas. 4 and 5.

ELEVATION VIEW

Fig. 2. System details, Test No. MWTC-1 (Winkelbauer et al., 2014).

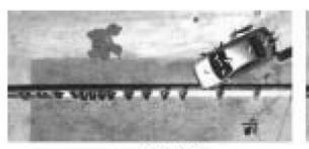

$0.000 \mathrm{sec}$

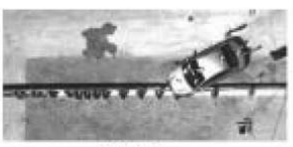

$0.044 \mathrm{sec}$

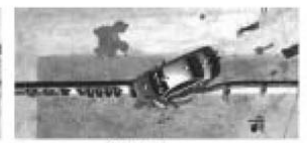

$0.152 \mathrm{sec}$

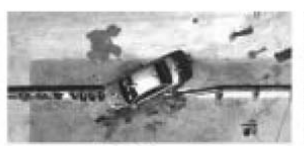

$0.248 \mathrm{sec}$

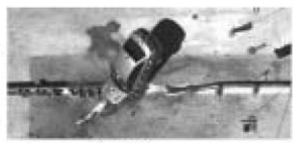

$0.710 \mathrm{sec}$
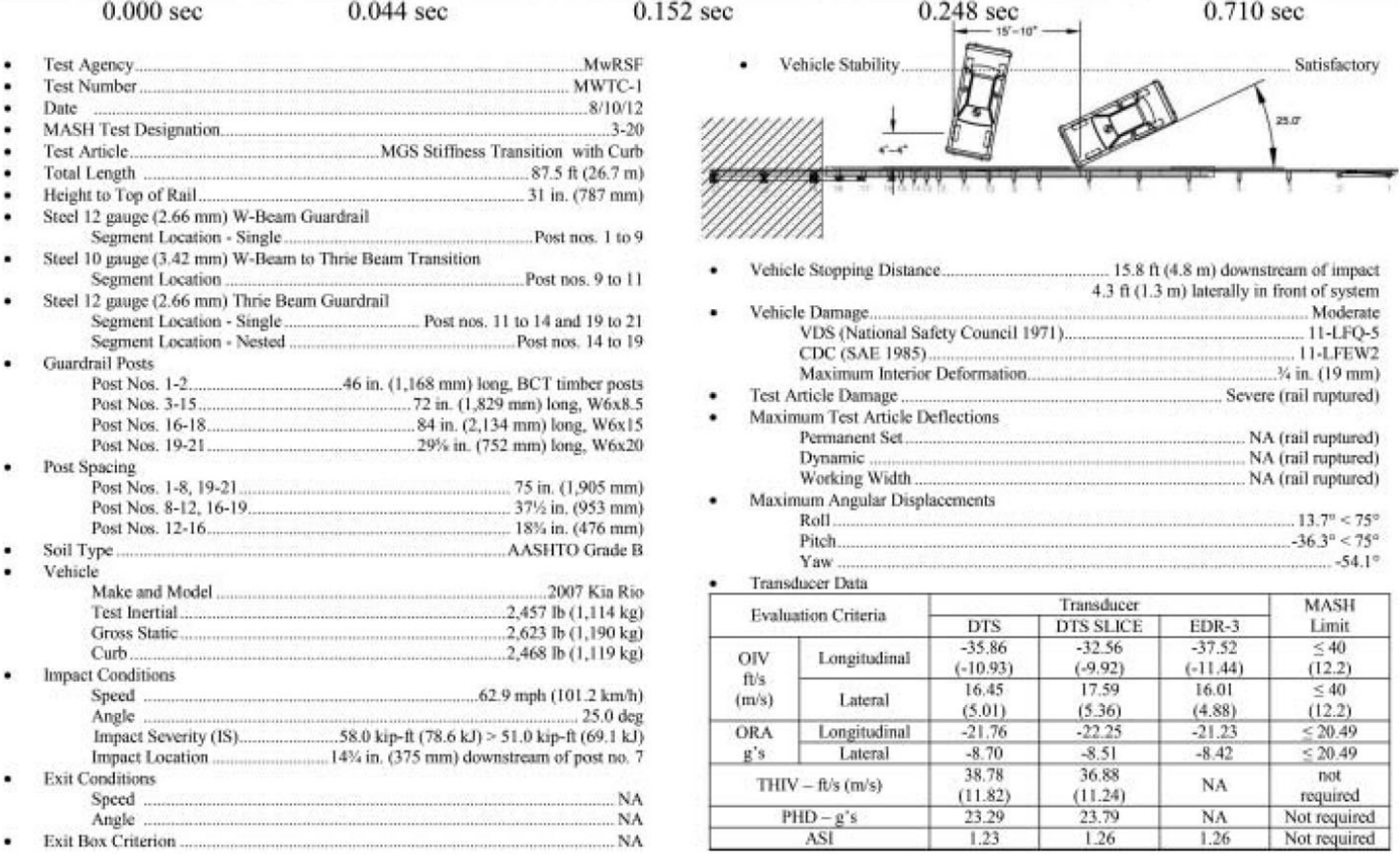

- Veticle Stopping Distance............................. $15.8 \mathrm{nt}(4.8 \mathrm{~m})$ downstream of impact

- Vehicle Damage...n_... $4.3 \mathrm{ft}(1.3 \mathrm{~m})$ laterally in front of system VDS (National Safety Council 1971)............................... MQ-5

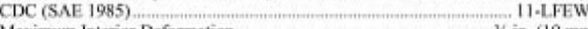

- Test Article Damage $\quad$ Severe frail ruptured)

Maximum Test Article Deflections

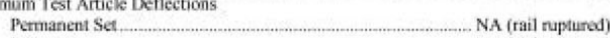

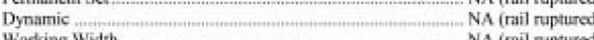

Wooking Width ............................................ (rail rupturod)
Maximum Angular Displacements

Roll $\quad 13.7^{\circ}<75^{\circ}$

Yaw

\begin{tabular}{|c|c|c|c|c|c|}
\hline \multirow{2}{*}{\multicolumn{2}{|c|}{ Evaluation Criteria }} & \multicolumn{3}{|c|}{ Transducer } & \multirow{3}{*}{$\begin{array}{c}\text { MASH } \\
\text { Limit } \\
\leq 40 \\
(12.2)\end{array}$} \\
\hline & & \multirow{2}{*}{$\begin{array}{c}\text { DTS } \\
-35.86 \\
(-10.93)\end{array}$} & \multirow{2}{*}{$\begin{array}{c}\text { DTS SLICE } \\
-32.56 \\
(-9.92)\end{array}$} & \multirow{2}{*}{$\begin{array}{c}\text { EDR-3 } \\
-37.52 \\
(-11,44)\end{array}$} & \\
\hline OIV & Longitudinal & & & & \\
\hline$(\mathrm{m} / \mathrm{s})$ & Lateral & $\begin{array}{l}16.45 \\
(5.01)\end{array}$ & $\begin{array}{l}17.59 \\
(5.36)\end{array}$ & $\begin{array}{l}16.01 \\
(4.88)\end{array}$ & $\begin{array}{l}\leq 40 \\
(12.2)\end{array}$ \\
\hline ORA & Longitudinal & -21.76 & -22.25 & -21.23 & $<20.49$ \\
\hline g's & Lateral & -8.70 & -8.51 & -8.42 & $\leq 20.49$ \\
\hline \multicolumn{2}{|c|}{ THIV - ftis (m/s) } & $\begin{array}{c}38.78 \\
(11.82)\end{array}$ & $\begin{array}{c}36.88 \\
(11.24)\end{array}$ & $\mathrm{NA}$ & $\begin{array}{c}\text { not } \\
\text { required }\end{array}$ \\
\hline \multirow{2}{*}{\multicolumn{2}{|c|}{ PHD $-g^{*} s$}} & 23.29 & 23.79 & $\mathrm{NA}$ & Not required \\
\hline & ASI & 1.23 & 1.26 & 1.26 & Not required \\
\hline
\end{tabular}

Fig. 3. Summary of test results, Test No. MWTC-1 (Winkelbauer et al., 2014). 

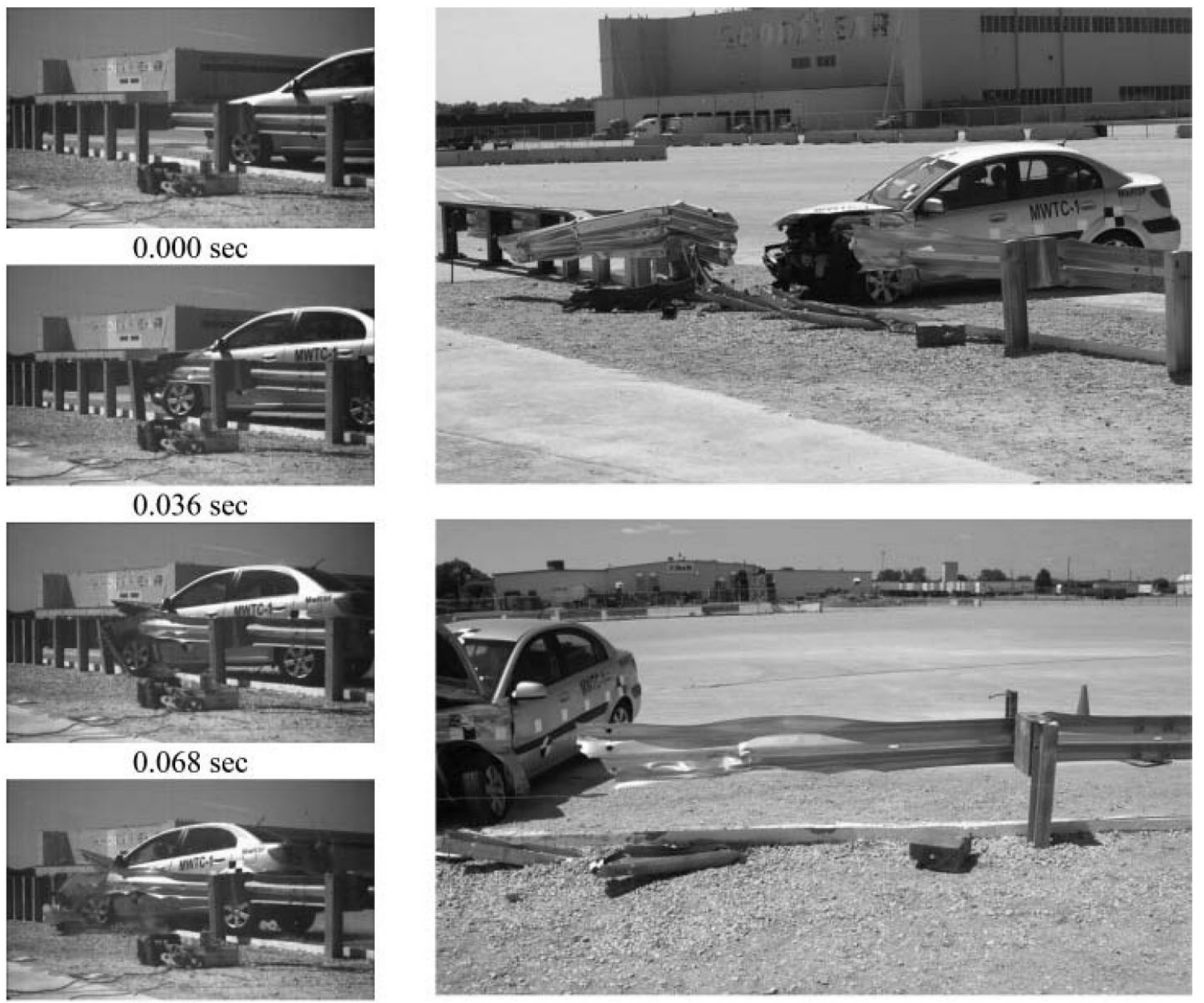

$0.068 \mathrm{sec}$

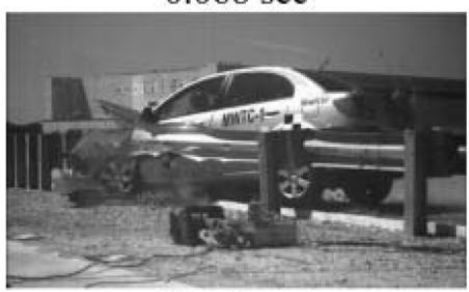

$0.110 \mathrm{sec}$

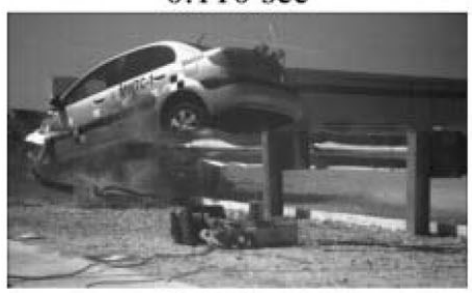

$0.314 \mathrm{sec}$

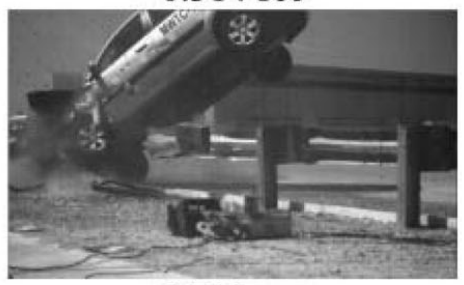

$0.710 \mathrm{sec}$

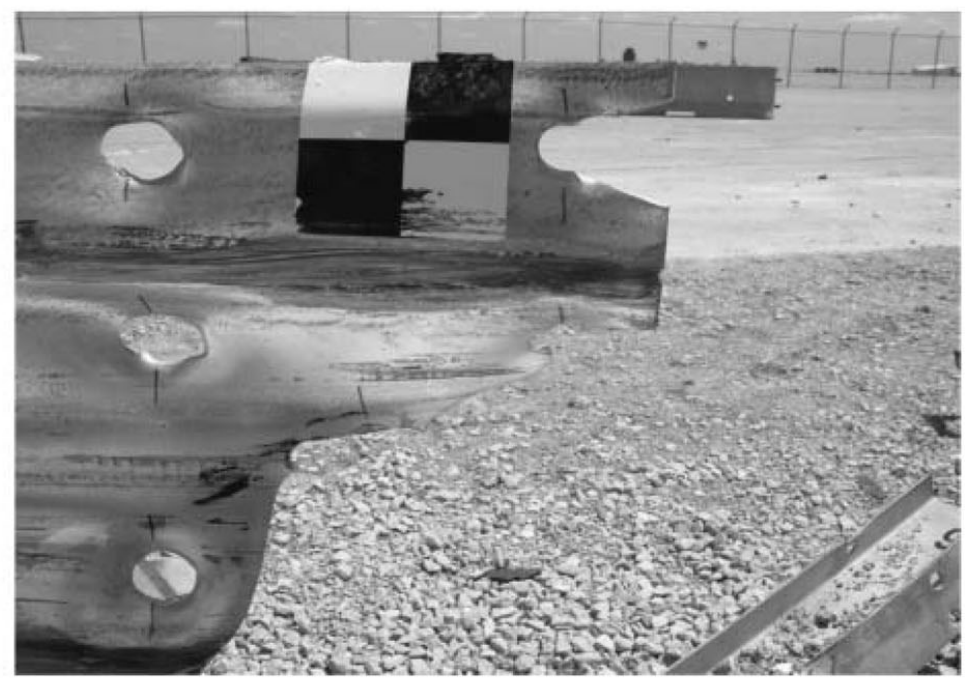

Fig. 4. Sequential photos and system damage, Test No. MWTC-1 (Winkelbauer et al., 2014). 


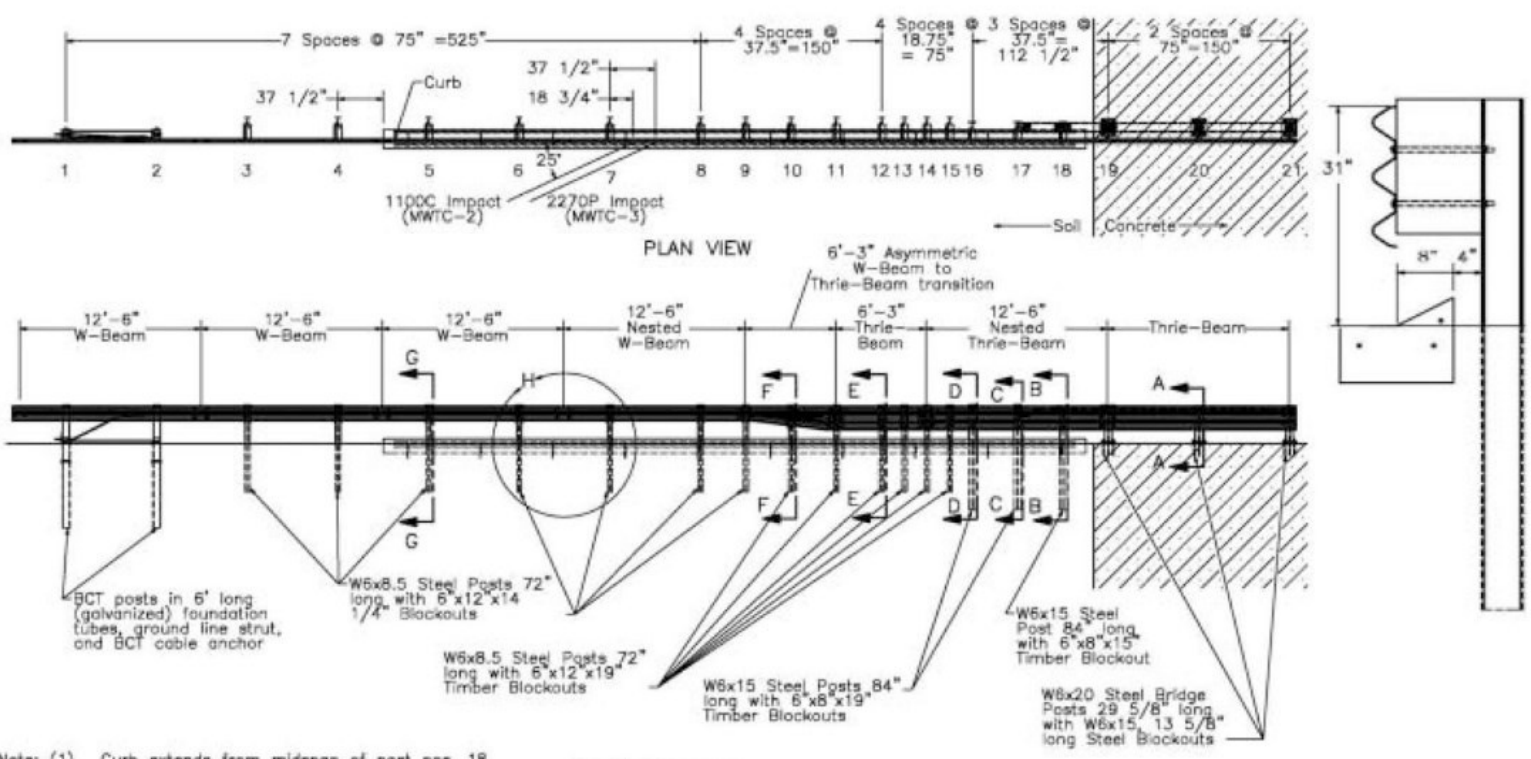

Note: (1) Curb extends trom midspan of post nos. ${ }^{18}$ and 19 to midspan of post nos. 4 and 5.
ELEVATION VIEW

Fig. 5. System layout, Test Nos. MWTC-2 and MWTC-3 (Winkelbauer et al., 2014).

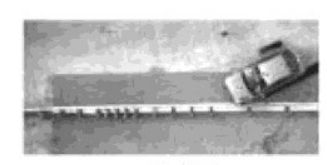

$0.000 \mathrm{sec}$

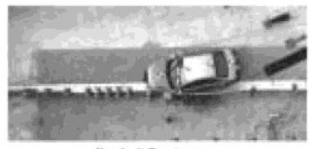

$0.162 \mathrm{sec}$

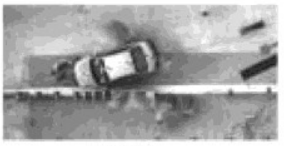

$0.412 \mathrm{sec}$

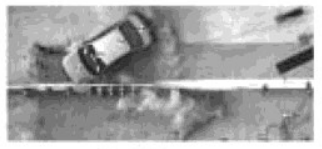

$0.558 \mathrm{sec}$

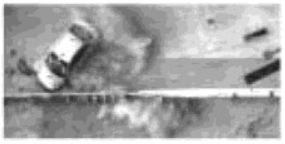

$0.772 \mathrm{sec}$

- Test Agency
Test Number
MwRSF
MWTC-2

\begin{tabular}{l} 
Test Number \\
Date \\
MASH Test Designation \\
\hline
\end{tabular}

- MASH Test Designation ........................... MGS Stiffiess Transition with Curth

- Total Lenyth _..__ $\quad 87.5 \mathrm{ft}(26.7 \mathrm{~m})$

- Height to Top of Rail.

Steel 12 gauge $(2.66 \mathrm{~mm})$ W-Beam Guardrail

12 gauge $(2.66 \mathrm{~mm})$ W-Beam Guardrail _. Post no 1 to Splice 67
Segnent Location - Single.

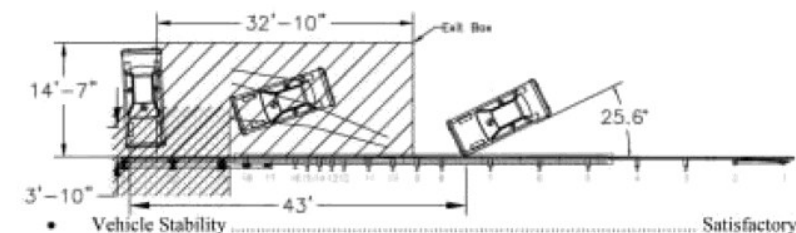

- Vehicle Stability

- Vehicle Stopping Distance

43.0 ft $(13.1 \mathrm{~m})$ downstrenam of impory

$3.8 \mathrm{ft}(1.2 \mathrm{~m})$ laterally in front of system

Segment Location Wost nos. 9 to 11

Segment Location ......
- Steel 12 gange (2.66 mm) Thrie Beam Guardrail

Segment Location - Single........... Post nos. 11 to 14 and 19 to 21

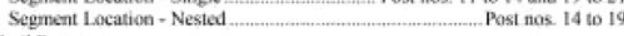

- Guardrail Posts

Post Nos. 1-2 _ _ . $\quad .46$ in. (1, $168 \mathrm{~mm})$ long, BCT timber posts Post Nos. $3.15 \ldots \ldots . .72$ in. $(1,829 \mathrm{~mm})$ long. W6x8.5 Post Nos. 16-18_________. $\quad 84$ in. $(2,134 \mathrm{~mm})$ long. W6x15

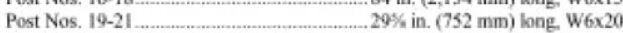

- Post Spacing

Post Nos. 1-8, 19-21 . 75 in. $(1,905 \mathrm{~mm})$ Post Nos, 8-12,16-19 $\quad . \quad 371 / 2$ in. $1953 \mathrm{~mm}$ Post Nos. $12-16 \quad 18 \%$ in. $(476 \mathrm{~mm})$

- Soil Type …_ AASHTO Grade B Vehicle

Make and Model ._._. 2007 Kia Rio

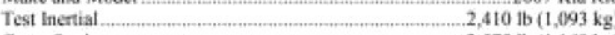

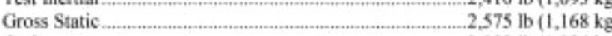

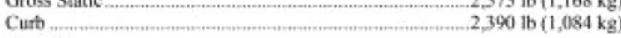

- Impact Conditions

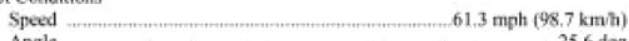

Angle $\quad 56.5 \mathrm{kip}=\mathrm{ft}(76.6 \mathrm{~kJ})=51.0 \mathrm{kip}-\mathrm{A}(69 . \mathrm{kJ})$ (206 - Exit Conditions

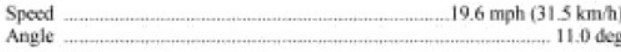

- Exit Box Criterion

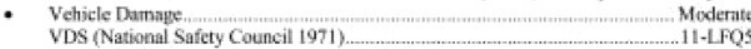
CDC (SAE 1985) Maximum Interior Deformation.............. I in. (25 man)

- Test Article Damage Moderate

- Maximum Test Article Deflections

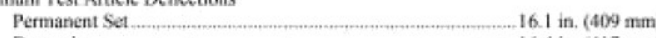

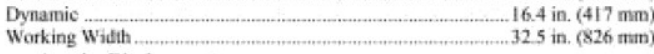

- Maximum Angular Displacements Roll $\quad \begin{array}{r}-13.7^{\circ}<75^{\circ} \\ \text { Pitch }\end{array}$ Yaw not

\begin{tabular}{|c|c|c|c|c|c|}
\hline \multirow{2}{*}{\multicolumn{2}{|c|}{ Evaluation Criteria }} & \multicolumn{3}{|c|}{ Transducer } & \multirow{3}{*}{$\begin{array}{c}\begin{array}{c}\text { MASH } \\
\text { Limit }\end{array} \\
\leq 40 \\
(122) \\
\end{array}$} \\
\hline & & \multirow{2}{*}{$\begin{array}{c}\text { DTS } \\
-22.23 \\
(6,78)\end{array}$} & \multirow{2}{*}{$\begin{array}{c}\text { DTS SLICE } \\
-23.04 \\
(-7.02)\end{array}$} & \multirow{2}{*}{$\begin{array}{l}\text { EDR-3 } \\
-24.21 \\
(=7.38)\end{array}$} & \\
\hline OIV & Longitudinal & & & & \\
\hline $\begin{array}{c}11 / \mathrm{s} \\
(\mathrm{m} / \mathrm{s})\end{array}$ & Lateral & $\begin{array}{l}22.53 \\
(6.87)\end{array}$ & $\begin{array}{l}24.14 \\
(7.36)\end{array}$ & $\begin{array}{l}21.19 \\
(6.46)\end{array}$ & $\begin{array}{r}540 \\
(12.2)\end{array}$ \\
\hline ORA & Longitudinal & -15.65 & .16 .58 & .11 .72 & $\leq 20.49$ \\
\hline g's & Lateral & 13.45 & 12.45 & 10.88 & $\leq 20.49$ \\
\hline \multicolumn{2}{|c|}{ THIV $-\mathrm{ft} / \mathrm{s}(\mathrm{m} / \mathrm{s})$} & $\begin{array}{l}31.66 \\
(9.65) \\
\end{array}$ & $\begin{array}{l}31.79 \\
(9.69)\end{array}$ & NA & $\begin{array}{c}\text { not } \\
\text { required }\end{array}$ \\
\hline \multicolumn{2}{|c|}{ PHD $-g$ 's } & 15.69 & 18.84 & NA & Not required \\
\hline \multicolumn{2}{|c|}{ ASI } & 1.32 & 1.40 & 1.27 & Not required \\
\hline
\end{tabular}

Fig. 6. Summary of test results, Test No. MWTC-2 (Winkelbauer et al., 2014). 


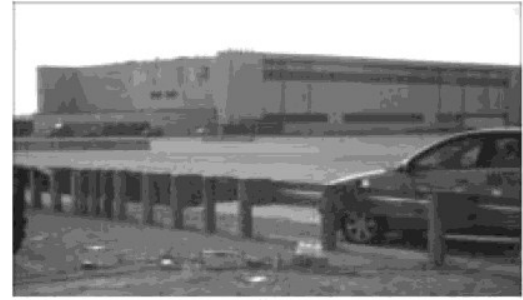

$0.000 \mathrm{sec}$

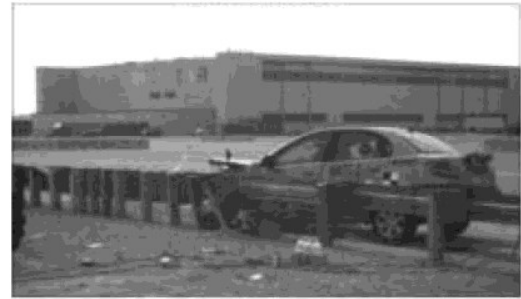

$0.076 \mathrm{sec}$

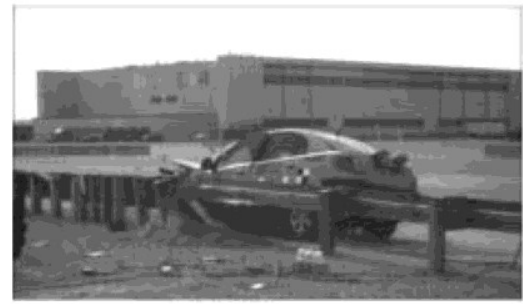

$0.138 \mathrm{sec}$

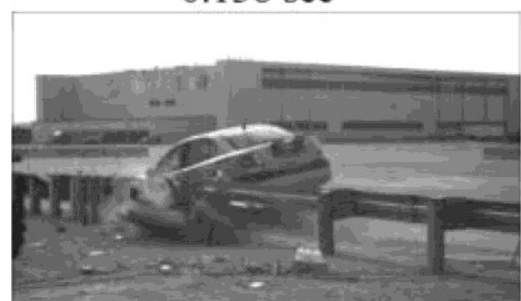

$0.306 \mathrm{sec}$

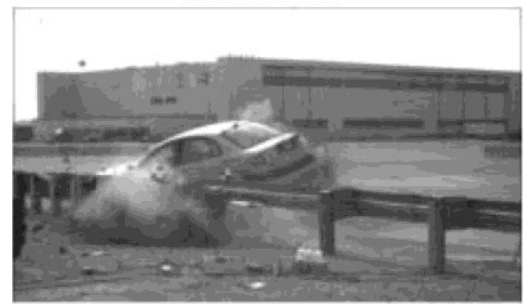

$0.472 \mathrm{sec}$

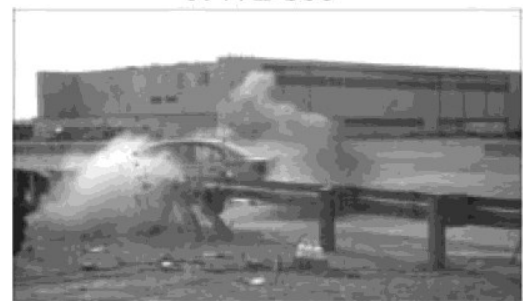

$0.772 \mathrm{sec}$
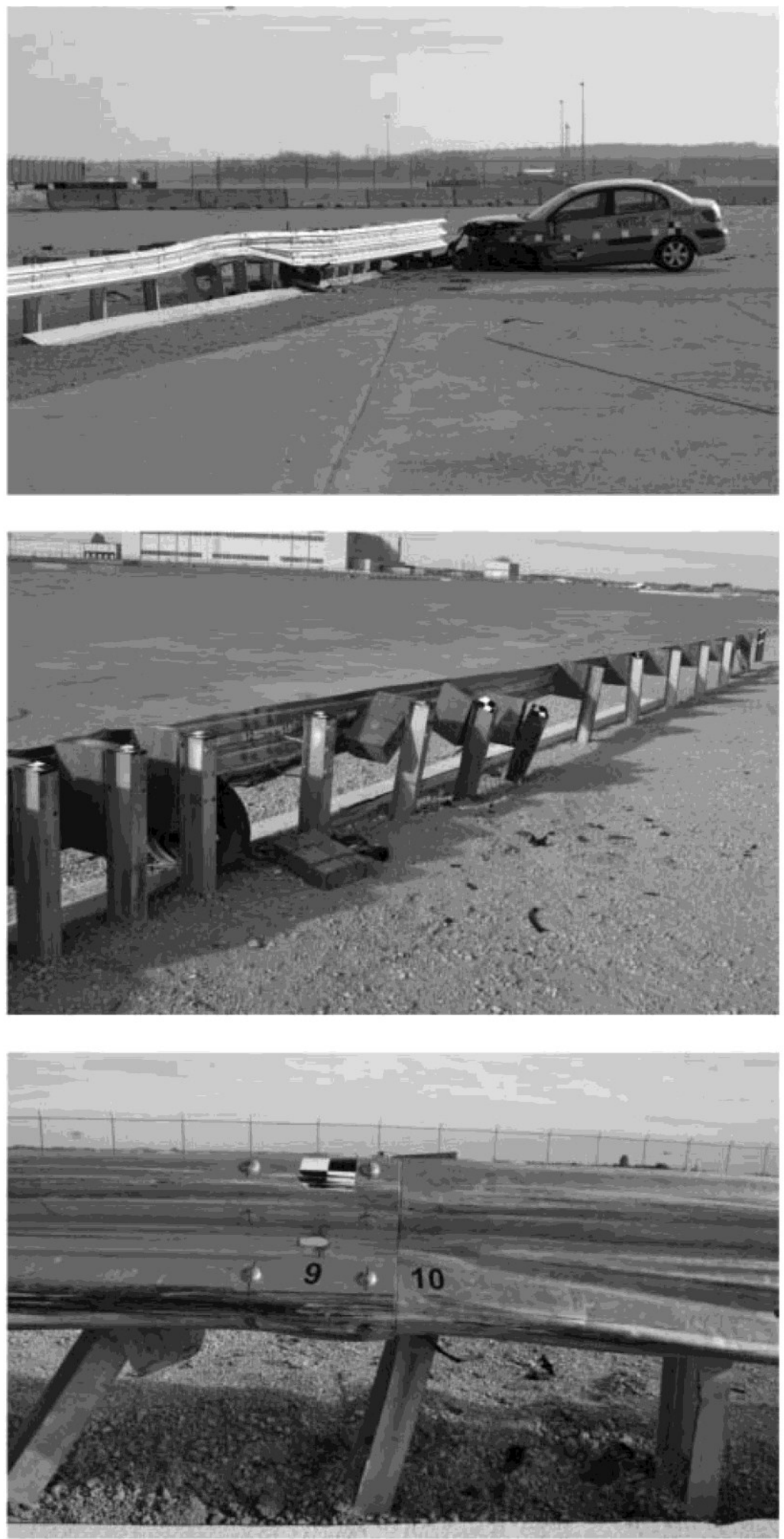

Fig. 7. Sequential photos and system damage, Test No. MWTC-2 (Winkelbauer et al., 2014). 


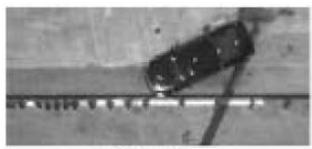

$0.000 \mathrm{sec}$

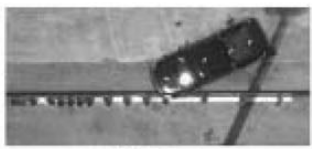

$0.013 \mathrm{sec}$

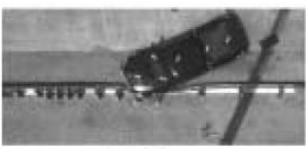

$0.035 \mathrm{sec}$

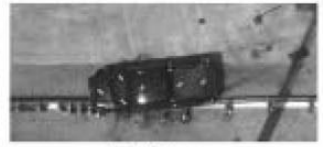

$0.096 \mathrm{sec}$

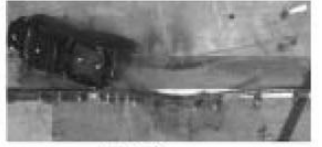

$0.292 \mathrm{sec}$

- Test Agency _.................... MwRF

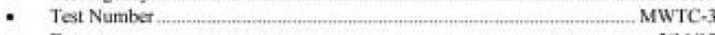

- Date

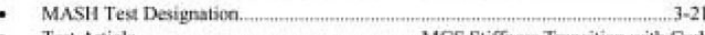

- Test Article _ MGS Stiffness Transition with Curb

- Total Length . $\quad 87.5 \mathrm{ft}(26.7 \mathrm{~m}$

- Height to Top of Rail ............... 31 in $(787 \mathrm{~mm})$

Steel 12 gauge (2.66 mm) W-Beam Guardrail

Segment Location - Single _._............................... Post no. I to Splice 6/7 Segment Location - Nested ........................................ Splice 6/7 to Post no. 9

- Steel 10 gauge (3,42 mm) W-Beam to Thrie Beam Transition

Segment Location

Post nos, 9 to 11

- Steel 12 gauge $(2.66 \mathrm{~mm})$ Thrie Beam Guardrail

Segment Location - Single _........................ Post nos. 11 to 14 and 19 to 21

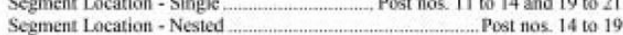

- Guardrail Posts

Post Nos, 1.2 _ 46 in. (1.168 mm) long, BCT timber posts

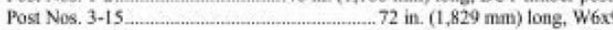

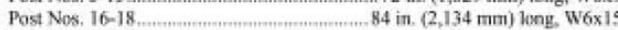

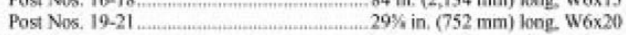

- Post Spacing

Post Nos. 1-8, 19-21 _................................................ 75 in. (1,905 mm

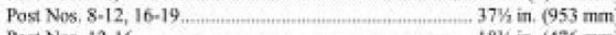
Post Nos. 12-16 _..____ _ _ _ $18 \%$ in. $(476 \mathrm{~mm})$

Vehicle
Make and Model

2006 Dodge Ram 1500 Quad Cab Test Inertial _._._. $4,969 \mathrm{lb}(2,254 \mathrm{~kg})$

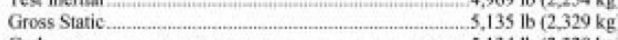
Curb $5,134 \mathrm{lb}(2,329 \mathrm{~kg})$

- Impact Conditions Speed ............ $61.0 \mathrm{mph}(98.1 \mathrm{~km} / \mathrm{h})$

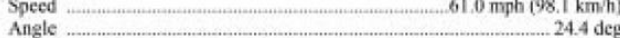

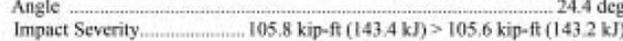

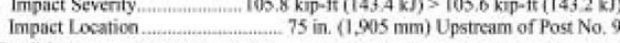
- Exit Conditions
Speed
$38.3 \mathrm{mph}(61.7 \mathrm{~km} / \mathrm{h}$

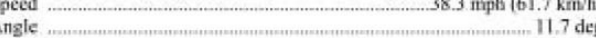

- Exit Box Criterion

Passed

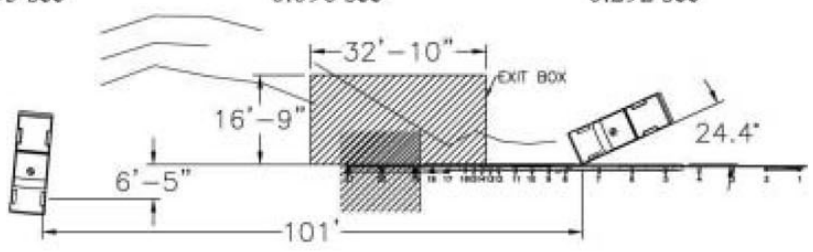

- Vehicle Stability

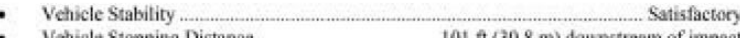

. $6.41(2.0 \mathrm{~m})$ laterally behind system

- Vehicle Damage

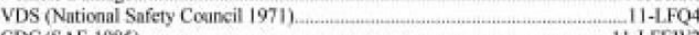

CDC (SAE 1985) $\quad \begin{gathered}11-\text { LFEW2 } \\ \text { Maxisum Interior Deformation }\end{gathered}$

Maximum Interior Deformation....unn

- Test Article Damage

Moderate

Maximum Test Article Deflections

Permanent Set _._. 17.8 in. (452 mm)

Dynamic

- Maximum Angular Displacements

Roll $\ldots \ldots \ldots \ldots . . .21 .8^{2}<75^{\circ}$

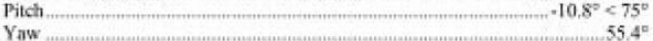

- Transtucer Data

\begin{tabular}{|c|c|c|c|c|c|}
\hline \multirow{2}{*}{\multicolumn{2}{|c|}{ Evaluation Criteria }} & \multicolumn{3}{|c|}{ Transducer } & \multirow{3}{*}{$\begin{array}{c}\begin{array}{c}\text { MASH } \\
\text { Limit }\end{array} \\
\leq 40 \\
(12.2)\end{array}$} \\
\hline & & \multirow{2}{*}{$\begin{array}{c}\text { DTS } \\
-17.62 \\
(-5.37)\end{array}$} & \multirow{2}{*}{$\begin{array}{c}\text { DTS SLICE } \\
-17.46 \\
(-5.32)\end{array}$} & \multirow{2}{*}{$\begin{array}{c}\text { DTS } \\
-18.77 \\
(-5.72)\end{array}$} & \\
\hline OIV & Longitudinal & & & & \\
\hline (mis) & Lateral & $\begin{array}{l}16.31 \\
(4.97)\end{array}$ & $\begin{array}{l}17.79 \\
(5.42)\end{array}$ & $\begin{array}{l}17.11 \\
(5.22)\end{array}$ & $\begin{array}{l}540 \\
(12.2)\end{array}$ \\
\hline \multirow{2}{*}{$\begin{array}{c}\text { ORA } \\
\text { g's }\end{array}$} & Longitudinal & -12.52 & -1229 & -13.07 & $\leq 20.49$ \\
\hline & Lateral & 10.94 & 9.18 & 10.12 & $\leq 20.49$ \\
\hline \multicolumn{2}{|c|}{ THIV - $\mathrm{f} / \mathrm{s}(\mathrm{m} / \mathrm{s})$} & $\begin{array}{l}23.02 \\
(7.02)\end{array}$ & $\begin{array}{l}23.75 \\
(7.24)\end{array}$ & NA & $\begin{array}{l}\text { not } \\
\text { required }\end{array}$ \\
\hline \multicolumn{2}{|c|}{ PHD $-g^{\prime} 3$} & 15.21 & 14.83 & NA & Not roquired \\
\hline \multicolumn{2}{|c|}{ ASI } & 0.88 & 0.93 & 0.92 & Not required \\
\hline
\end{tabular}

Fig. 8. Summary of test results, Test No. MWTC-3 (Winkelbauer et al., 2014). 

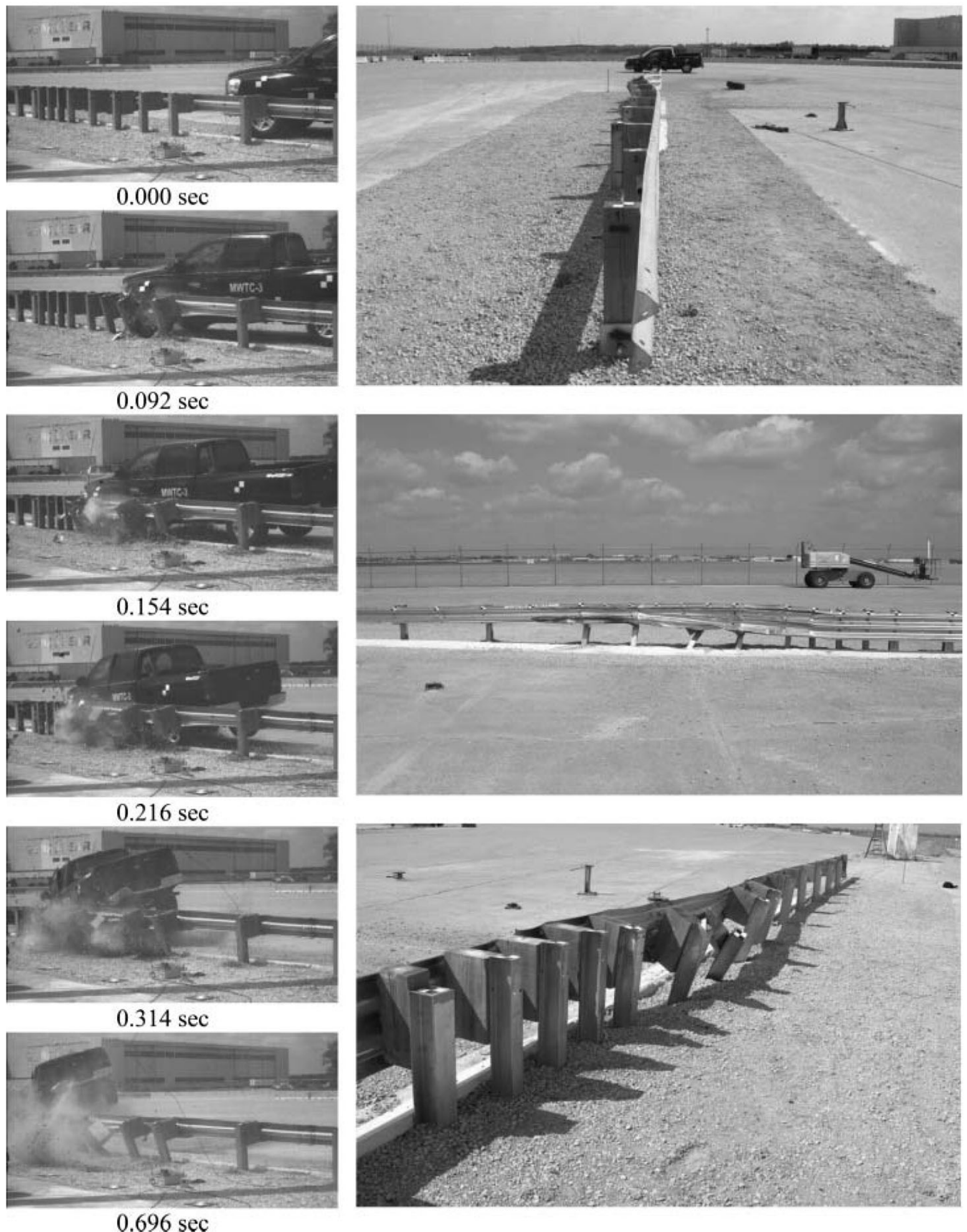

Fig. 9. Sequential photos and system damage, Test No. MWTC-3 (Winkelbauer et al., 2014). 


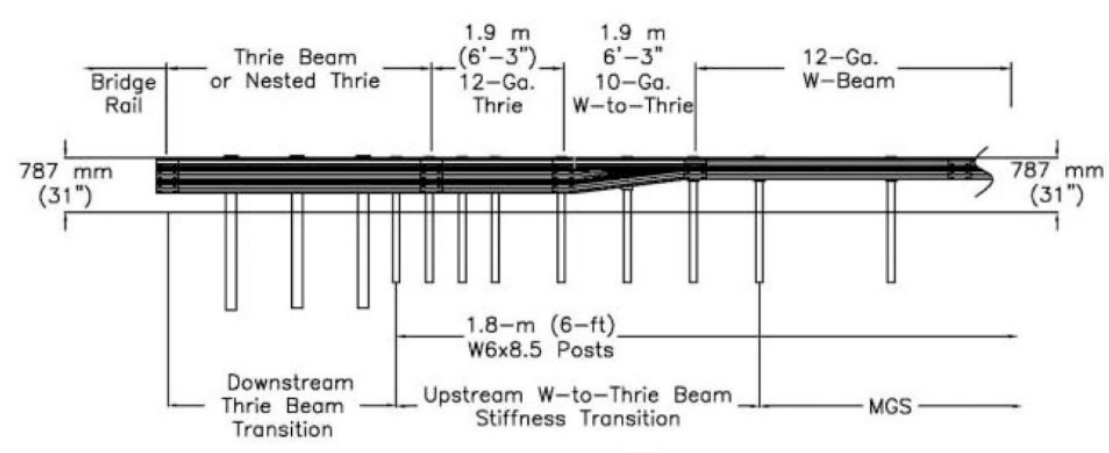

(a)

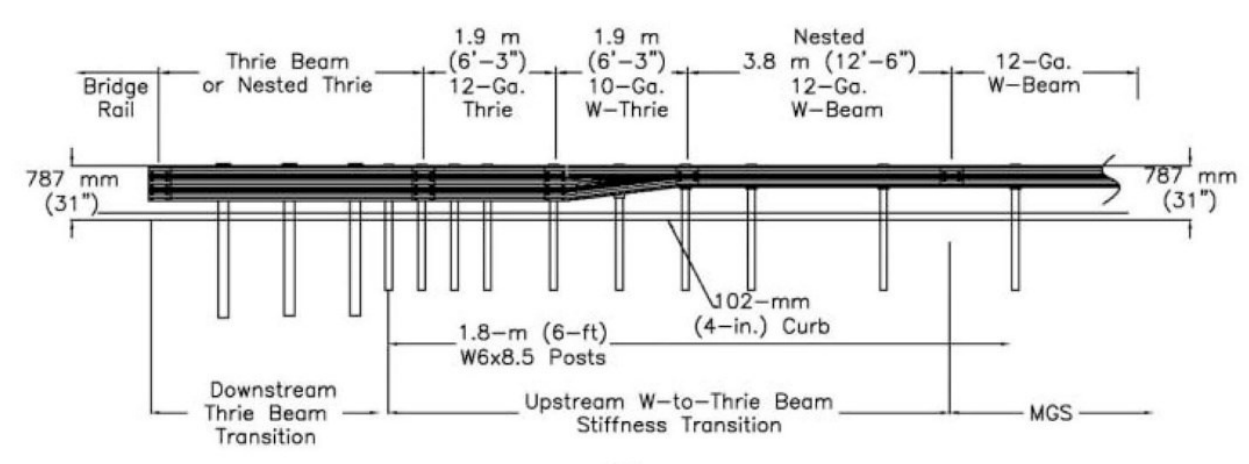

(b)

Fig. 10. Midwest Guardrail System to thrie beam stiffness transitions details (a) without a curb and (b) with or without a curb, 102-mm (4-in.) maximum curb height (Winkelbauer et al., 2014).

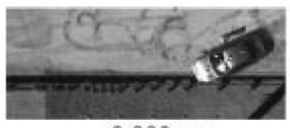

$0.000 \mathrm{sec}$

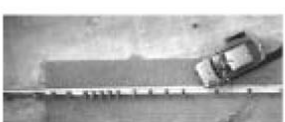

$0.000 \mathrm{sec}$

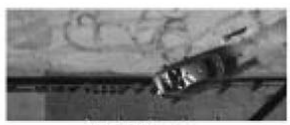

$0.100 \mathrm{sec}$

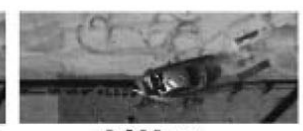

$0.200 \mathrm{sec}$

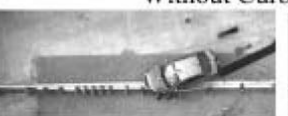

$0.100 \mathrm{sec}$

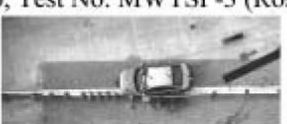

$0.200 \mathrm{sec}$

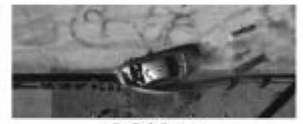

$0.300 \mathrm{sec}$

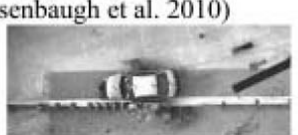

$0.300 \mathrm{sec}$

With Curb, Test No. MWTC-2 (Winkelbauer 2014)

(a) Small Car Performance

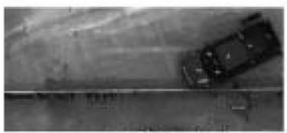

$0.000 \mathrm{sec}$

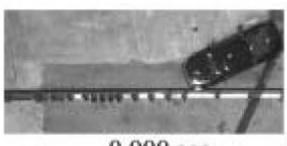

$0.000 \mathrm{sec}$

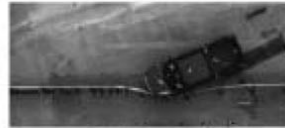

$0.100 \mathrm{sec}$

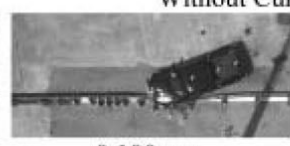

$0.100 \mathrm{sec}$

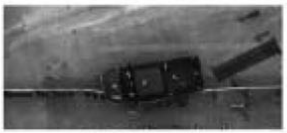

$0.200 \mathrm{sec}$

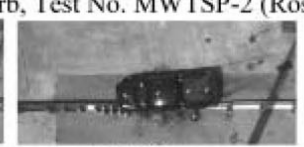

$0.200 \mathrm{sec}$

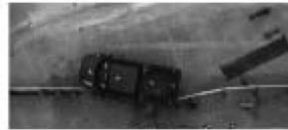

$0.300 \mathrm{sec}$

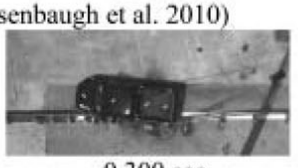

$0.300 \mathrm{sec}$ With Curb, Test No. MWTC-3 (Winkelbauer 2014)

(b) Pickup Truck Performance

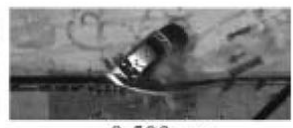

$0.500 \mathrm{sec}$

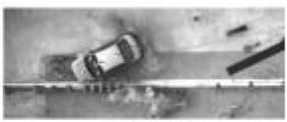

$0.500 \mathrm{sec}$

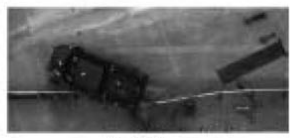

$0.400 \mathrm{sec}$

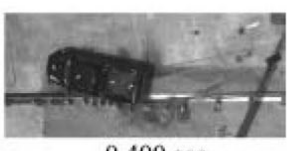

$0.400 \mathrm{sec}$

Fig. 11. Comparison of Midwest Guardrail System upstream stiffness transition performance. 